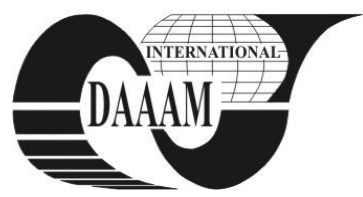

Annals of DAAAM for 2011 \& Proceedings of the 22nd International DAAAM Symposium, Volume 22, No. 1, ISSN 1726-9679 ISBN 978-3-901509-83-4, Editor B. Katalinic, Published by DAAAM International, Vienna, Austria, EU, 2011 Make Harmony between Technology and Nature, and Your Mind will Fly Free as a Bird Annals \& Proceedings of DAAAM International 2011

\title{
INFRARED SPECTROSCOPY OF THE REGENERATED MINERAL INSULATING OIL
}

\author{
PROSR, P[avel]; POLANSKY, R[adek] \& MENTLIK, V[aclav]
}

\begin{abstract}
Infrared spektroscopy is a measuring technique using different material ability to absorb the frequence of IR ray. Based on absorbed (or passed through) frequency spektrum, it is possible to determine different chemical compounds, molecular structure in the sample and their changes in consequence of ageing process. There are several measuring techniques of Infrared spectroscopy. Attenuated Total Reflectance technique (ATR) and measuring in transmission mode are the most widely used ones. The main aim of the paper is to demonstrate the difference in the results of different techniques of infrared spectroscopy and determine the way of interpretation of obtained spectra.
\end{abstract}

Key words: infrared spectroscopy, insulating oil, ATR technique, absorbance

\section{INTRODUCTION}

Problems of identification of different material components are considered to be very important objective. For this purpose, Infrared Spectroscopy has been successfully used, mainly in chemical industry (Heise et al., 1998), food processing industry (Downey, 1998), (Zhang et al., 2010) or in medicine (Jackson \& Mantsch, 1997), (Jackson et al., 1997). Our objective is to apply Infrared Spectroscopy into electrical technology branch, to a measurement and interpretation of insulating liquids spectra respectively. In this manner, it is possible to identify the beginning ageing process caused by thermal oxidation or nitration of the oil.

\section{INFRARED SPECTROSCOPY OF INSULATING LIQUIDS}

As mentioned before, among the most widely known techniques of the infrared spectroscopy of samples in liquid state belong Attenuated Total Reflectance technique (ATR) and measuring in transmission mode.

2.1 Measuring of FT-IR spectra using Attenuated Total Reflectance technique (ATR)

Figure 1 shows a measuring principle of ATR technique, a construction of ATR measurement is illustrated in Fig. 2.

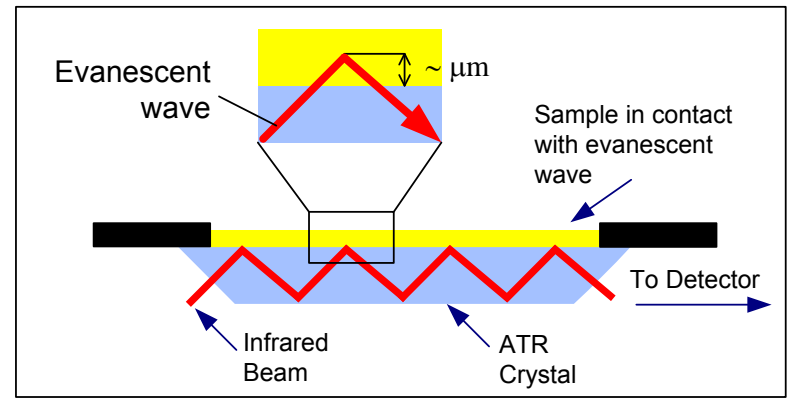

Fig. 1. Measuring principle of ATR technique
The sample is placed on a detection crystal when being measured. A part of the IR ray aiming at the sample causes absorption in the sample when passing through the crystalsample interface (evanescent wave) and thus weakens this part in the final spectrum.

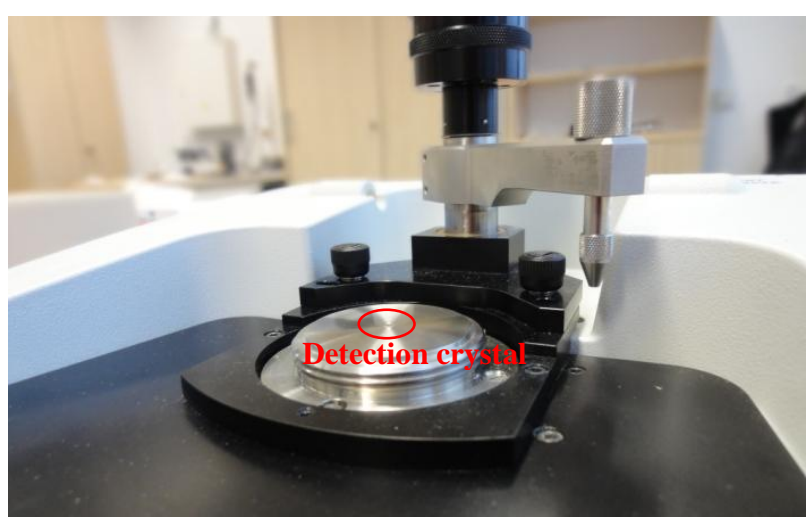

Fig. 2. Construction of Attenuated Total Reflectance measuring

\subsection{Measuring of FT- IR spectra in transmission mode}

Measuring technique in transmission mode focuses on detection of IR ray passing through the liquid sample placed in a cuvette (see Fig. 3). The sample is applied to the cuvette with a syringe.

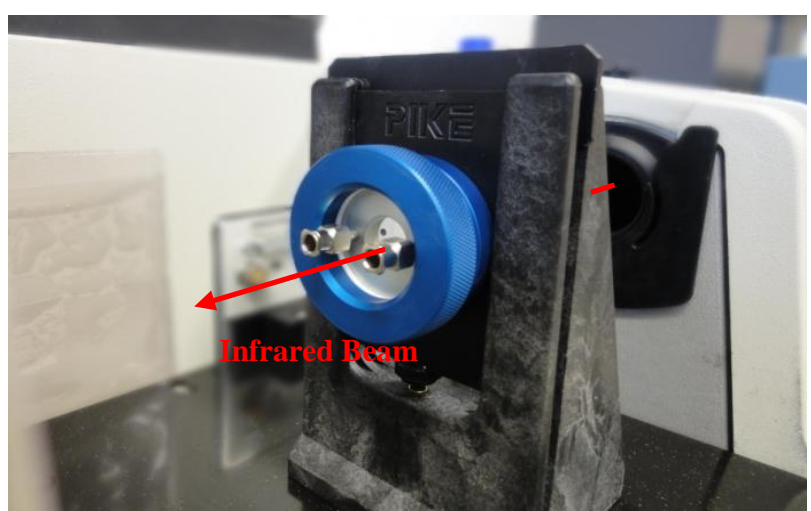

Fig. 3. Construction of an FT-IR Transmission cell

Optical path of the IR ray is chosen according to the measured liquid in the range from 0,2 to $0,5 \mathrm{~mm}$. $\mathrm{KBr}$ or $\mathrm{NaCl}$ are thought as the most suitable materials for the cuvette, however they have inconvenient hygroscopic properties. Hence it is necessary to prevent them from water or water vapour.

\section{IR APPLICATION TO INSULATING OILS ANALYSIS}

The main aim of the paper is to demonstrate the difference in the results of different techniques of infrared spectroscopy 
and determine the way of interpretation of obtained spectra. As noted previously, thermal oxidation and nitration are the most important processes that can be detected by FT-IR technique. (Robinson \& Hons, 2001).

\subsection{Thermal oxidation}

Oxidation, as a reaction of oxygen and oil molecules resulting in degradation of the insulating oil properties, is largely accelerated by increased temperature, whereas increase of temperature by $10^{\circ} \mathrm{C}$ leads to approx. doubling of oxidation rate.

\subsection{Nitration}

Thermal oxidation is usually accompanied by nitration. It is a process when organic compounds turn into nitrogen oxides ( $\mathrm{NO}, \mathrm{NO}_{2}$ and $\mathrm{N}_{2} \mathrm{O}_{4}$ ) at increased temperature. These oxides are then in contact with the oil, which results in organic nitrates. Analogous to oxidation, nitration effects the oil quality, e.g. by viscosity increase or creation of insoluble substances and sediments (Robinson, 2001).

\section{RESULTS AND DISCUSSION}

Infrared spectra were recorded on insulating oil on Nicolet 380 spectrometer. The measurement by ATR technique was proceeded with $\mathrm{ZnSe}$ crystal, when 32 scans with a resolution of $4 \mathrm{~cm}^{-1}$ were collected for sample. Measuring in transmission mode was proceeded with a resolution of $1 \mathrm{~cm}^{-1}$ in $\mathrm{BaF}_{2}$ cell with thickness of $1 \mathrm{~mm}$. The subsequent analysis of measured spectra was performed by OMNIC software. Figures 3 and 4 present the obtained spectra.

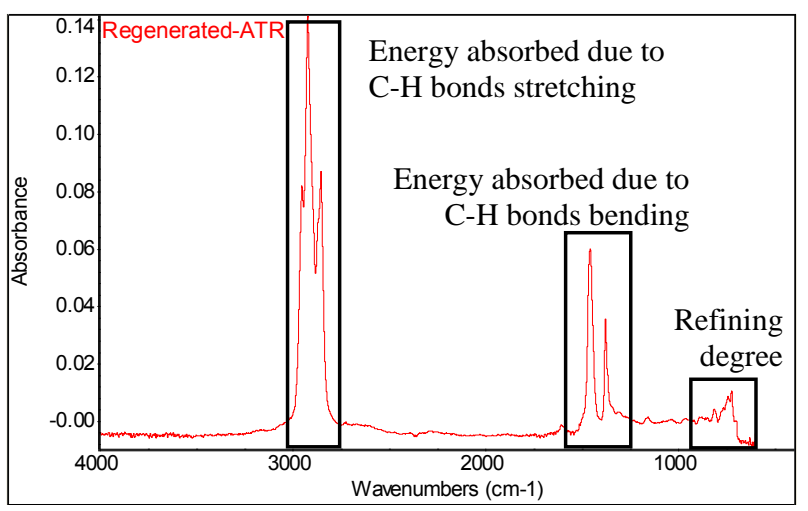

Fig. 3. ATR Spectrum

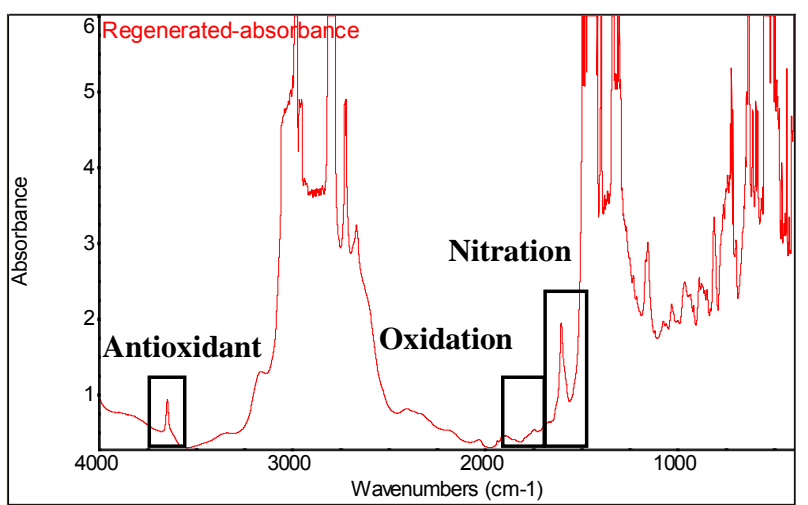

Fig. 4. Spectrum from the transmission mode of measurement

As obvious from previous figures, sensitivity of the measuring in transmission mode is much higher compared to ATR. It enables to identify specific processes proceeding in the oil more easily. The oil oxidation is detected by the presence of $1700 \mathrm{~cm}^{-1}$ band. Slight disadvantage of the interpretation of the spectrum in this frequency area is fact that detection of oxidation band can be interfered by carbonyl group (also present in the frequence around $1700 \mathrm{~cm}^{-1}$ ). As there is a spectrum of regenerated oil in Fig. 4, only small oxidative band can be observed. On the contrary, the nitrate band (a band of nitrate $-\mathrm{O}-\mathrm{NO}_{2}$ bonds) is not in most cases interfered by immediate bands and it is possible to detect it without any problems. Nitration products have an intensive characteristic absorbance from 1650 to $1600 \mathrm{~cm}^{-1}$.

\section{CONCLUSION}

Hence thermal oxidation and nitration influence the insulating oil properties negatively, the identification of these processes in mineral insulating oil is considered as very important objective in energetics. The oxidation products such as aldehydes, ketones, esters, carbonates and carboxylic acids occur during the oil oxidation. All these chemicals are of polar character and that is why they affect the final properties of nonpolar oil.

Oxidation products, mainly acids, support the increase of oil acidity and thus contribute to the corrosive activity of the oil. Moreover, the oxidation products cumulate in the oil and their subsequent reaction can cause the increase of oil viscosity, which is very undesirable when considering the usage of the insulating oil as the cooling liquid in power transformers. Furthermore, high amount of oxidation products in the oil results in the increase of carbonizing substances and carbon deposits. Nitrates creating together with the oxidation products affect the oil properties also very negatively. The measuring in transmission mode was proven as more convenient applied technique for detection of nitrates and oxidation products presence in the insulating oil. As obvious from obtained spectra, the technique of measuring in transmission mode is expressively more sensitive compared to ATR method, even though there is slight disadvantage in uneasy cleaning of the measuring cuvette.

\section{ACKNOWLEDGEMENTS}

This article was carried out by the help of Ministry of Education, Youth and Sports of Czech Republic, MSM 4977751310 - Diagnostics of Interactive Processes in Electrical Engineering.

\section{REFERENCES}

Downey G. (1998). Food and food ingredient authentication by mid-infrared spectroscopy and chemometrics, rends in analytical chemismy. TrAC Trends in Analytical Chemistry, Vol. No. 17, (August 1998), 418-424, ISSN 0165-9936

Heise, H.M.; Kupper L.; Butvina, L. N. (1998). Attenuated total reflection mid-infrared spectroscopy for clinical chemistry applications using silver halide fibers. Sensors and Actuators B Vol., No. 51, (August 1998) 84-91, ISSN 0925-4005

Jackson M.; Mantsch H. H. (1997). The medical challenge to infrared spectroscopy. Journal of Molecular Structure, Vol., No. 408/409, (June 1997) 105-111, ISSN 0022-2860

Jackson M.; Sowa M. G.; Mantsch H. H. (1997). Infrared spectroscopy: a new frontier in medicine. Biophysical Chemistry, Volume 68, (October 1997), 109-125, ISSN 0301-4622

Robinson N.; Hons B. Sc. (2001). Monitoring oil degradation with infrared spectroscopy, Available from: http://www.wearcheck.com/literature/techdoc/WZA0 18.pdf Accessed:2011-01-17

Yan-ling Zhang; Jian-bo Chen; Yu Lei; Qun Zhou; Su-qin Sun; Isao Noda (2010). Discrimination of different red wine by Fourier-transform infrared and two-dimensional infrared correlation spectroscopy. Journal of Molecular Structure, Volume No. 974, (June 2010), 144-150, ISSN 0022-2860 